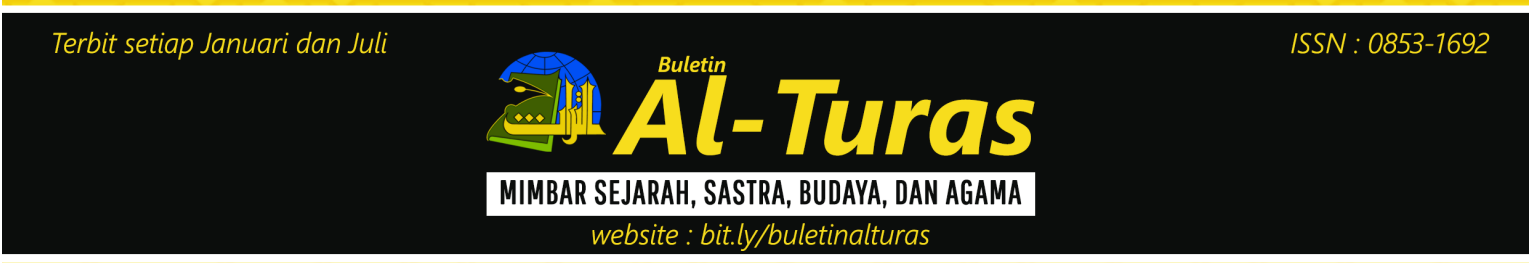

\title{
Arsip Sejarah Ormas Islam: Studi Kasus Penyelamatan Arsip Nadhlatul Ulama Dan Muhammadiyah
}

\author{
Lolytasari $^{1}$, Lilik Istiqoriyah ${ }^{2}$
}

\begin{abstract}
This article discusses the archives saving of the Islamic organizations in Indonesia as part of the historical development of Islamic syiar in Indonesia, which also shows the important role of Muslims for the progress of the nation. The purpose of this research is to know the saving effort of the archives conducted by two of the largest Islamic social organizations in Indonesia, namely NU and Muhammadiyah. The research uses qualitative approach with case study method. The results show that NU has begun rescue archives by submitting a static archive since 2014, although internal efforts have been made since 1983, while Muhammadiyah has done so since 2012. Structurally, both have specialized agencies whose task is related to this mission; Lakpesdam NU and the Library and Information Council of Muhammadiyah.The Islamic organization archives are also managed by competent human resources in the field supported by activist and intellectual leaders. Thus, it can be concluded that this Islamic mass organization has shown serious concern in saving Islamic archives through development of policy, plan and program procedure of archives.
\end{abstract}

Keywords: Archive saving; Organization of Islamic Societies

\section{Abstrak}

Artikel ini membahas tentang penyelamatan rekam jejak organisasi Islam di Indonesia sebagai bagian bukti dari sejarah perkembangan syiar Islam di Indonesia, yang juga menunjukkan peran penting umat Islam bagi kemajuan bangsa. Tujuan penelitian ini adalah untuk mengetahui upaya penyelamatan arsip yang tercipta di dua organisasi kemasyarakatan Islam terbesar di Indonesia, yakni NU dan Muhammadiyah. Pendekatan penelitian yang digunakan adalah kualitatif, dengan metode studi kasus. Hasil penelitian menunjukkan bahwa NU telah memulai penyelamatan arsip dengan menyerahkan arsip statis sejak 2014, meskipun upaya internal telah dilakukan sejak 1983, sementara Muhammadiyah telah melakukannya sejak 2012. Secara struktural ke duanya memiliki lembaga khusus yang salah satu tugasnya berkaitan dengan misi ini, masing-masing adalah Lakpesdam NU dan Majelis Pustaka dan Informasi Muhammadiyah. Kearsipan ormas Islam ini juga dikelolah oleh SDM yang berkompeten di bidangnya dengan didukung oleh tokoh-tokoh aktivis dan intelektual. Dengan demikian dapat disimpulkan bahwa ormas Islam ini telah menunjukkan perhatian serius dalam penyelamatan arsip keislaman melalui pengembangan kebijakan, rencana dan prosedur program kearsipan.

Kata kunci: Penyelamatan arsip; Organisasi Kemasyarakatan Islam

\footnotetext{
${ }^{1}$ Fakultas Ilmu Tarbiyah dan Keguruan, UIN Syarif Hidayatullah Jakarta Jakarta.

${ }^{2}$ Fakultas Ekonomi dan Bisnis, UIN Syarif Hidayatullah Jakarta
} 


\section{A. Pendahuluan}

\section{a. Latar Belakang}

Umat Islam di Indonesia telah lama berkembang melalui lahirnya kegiatankegiatan dan organisasi kemasyarakatan/ kemanusiaan. Di bawah tekanan penjajah kolonialis semakin menguatkan para aktivis gerakan Islam dan gerakan nasionalis untuk memimpin kesadaran untuk bergerak melalui jaringan masing-masing. Bisa dikatakan bahwa kemunculan organisasi sosial Islam memberikan akses terhadap kesadaran untuk memperjuangkan diri dan umat Islam sekaligus sebagai gerakan kebangkitan nasionalisme.

Perkembangan organisasi keagamaan di Indonesia adalah sejarah yang sangat panjang dari waktu sebelum kemerdekaan sampai dengan era modern. Nottingham menyebutkan organisasi keagamaan sebagai upaya terorganisir untuk menyebarkan agama baru, atau interpretasi baru terhadap agama-agama yang ada. Agama Islam berkembang baik secara lokal, nasional maupun internasional. Beberapa organisasi kemasyarakatan Islam terbesar secara nasional maupun lokal dengan fokus dan cakupan gerakan yang beragam, yakni: Nahdlatul Ulama (NU), Sarikat Islam (SI), Persatuan Tarbiyah Islamiyah (PERTI), Majelis Ulama Indonesia (MUI), Asosiasi Peningkatan Pendidikan Islam (GUPPI), Majelis Dakwah Islamiyah (MDI), Bahasa Indonesia Dewan Masjid (DMI), Asosiasi Intelektual Muslim Indonesia (ICMI), Himpunan Mahasiswa Islam (HMI), Serikat Mahasiswa Islam Indonesia (PMII), Aisyiah, Muslimat NU, dan sebagainya. Selain itu ada juga organisasi Islam yang bergerak di bidang dakwah dan pendidikan lokal seperti: majelis taklim, yayasan pendidikan islam, yayasan yatim, lembaga bimbingan dan konsultasi keislaman, dan sebagainya.

Jalannya organisasi dalam berbagai aspek kehidupan, tak terlepas dari arsip. Hal ini karena manusia selalu membutuhkan catatan atau rekaman dalam berbagai aktivitas yang dilakukan sebagai alat untuk kepentingan administrasi, hukum dan pembuktian. Sesuai dengan fungsinya, arsip dibuat berdasarkan bisnis pokoknya, dan misi dasar sebuah organisasi arsip adalah memilih, melestarikan dan menyediakan koleksi dalam perawatannya.

Arsip adalah dasar ingatan, tapi kenangan tidak cukup diungkap jika tidak diarsipkan. Jika dikaitkan dengan masa kejayaan Islam, maka Khalifah Umar bin Abdul Aziz (99-101 H) adalah khalifah yang pertama kali menyadari tertib arsip. Khalifah Umarlah yang pertama kali melakukan pembenahan administrasi di dunia Islam pada tahun $20 \mathrm{H}$, yang isinya adalah peraturan yang berkaitan dengan kekayaan negara. Pada saat itu Khalifah Umar menyadari pentingnya kebutuhan akan catatan pendapatan negara dan pengeluarannya. Selain itu, terdapat kebutuhan mendesak untuk mencatat siapa tentara yang harus dibayar dalam pembukuan. Saat itu pembukuan negara disebut sebagai dokumentasi rahasia negara. ${ }^{3}$

Gerakan tertib arsip oleh Khalifah Umar tersebut, dalam konteks saat ini dapat dianggap sebagai Pencanangan Gerakan Sadar Tertib Arsip sebagai Pilar Akuntabilitas atau yang dikenal dengans sebutan GETAR PIKAT (Gerakan Sadar Tertib Arsip sebagai Pilar Akuntabilitas) yang dikomandoi dan disosialisasikan oleh Arsip Nasional Republik Indonesia (ANRI). Gerakan ini

\footnotetext{
${ }^{3}$ Muhammad ASh-Shalabi, The Great Leader of Umar Bin Al-Khathab ; Kisah Kehidupan Dan Kepemimpinan Khalifah Kedua, 391-92.
} 
mulai diprogramkan sejak tahun 2017 , dimana institusi pendidikan, organisasi kemasyarakatan, dan arsip institusi lokal harus mengelola dan meyelamatkan arsip yang dihasilkannya dengan sistem yang baik.

\section{Permasalahan}

Kesadaran penyelamatan arsip merupakan bagian yang terpenting bagi organisasi dalam menyelamatkan aset dan meningkatkan akuntabilitasnya. Berbagai upaya telah dilakukan oleh pemerintahuntukmenyerukan organisasi bersama semua komponen masyarakat lainnya termasuk individu agar arsip yang tercipta dapat diselamatkan. Hal ini disebabkan karena arsip dapat mencerminkan sejarah panjang dari suatu organisasi. Upaya pemerintah tersebut tercermin dari terbitnya Undang-Undang Kearsipan pada tahun 1971 Nomor 7 tentang Ketentuanketentuan Pokok Kearsipan, yang menyebutkan bahwa Arsip Nasional (ANRI) wajib menyimpan, memelihara dan menyelamatkan arsip yang berasal dari Lembaga-lembaga Negara, Badanbadan Pemerintah Pusat, badan-badan swasta dan atau perorangan ${ }^{4}$. Kemudian Undang-Undang mengenai kearsipan ini diperbaharui pada tahun 2009.

Pembaharuan Undang-Undang Kearsipan tahun 2009 dilatar belakangi perluasan penyelamatan arsip statis yang tercipta pada skala nasional yang diterima dari lembaga negara, perusahaan, organisasi politik, organisasi kemasyarakatan dan perseorangan. ${ }^{5}$ Dalam UndangUndang ini sudah mulai muncul kata "organisasi kemasyarakatan". Artinya

${ }^{4}$ Republik Indonesia, “Undang-Undang Nomor 7 Tahun 1971 Tentang Ketentuan-Ketentuan Pokok Kearsipan," 4.

${ }^{5}$ Republik Indonesia, "Undang-Undang Republik Indonesia Nomor 43 Tahun 2009 Tentang Kearsipan," 17.
ANRI sebagai lembaga pembina sistem kearsipan nasional sudah memikirkan pengelolaan arsip yag berasal dari organisasi kemasyarakatan. Termasuk di dalamnya adalah organisasi kemasyarakatan Islam, yakni Nahdlatul Ulama (NU) dan Muhammadiyah. yang menjadi fokus penelitian ini.

Kedua organisasi tersebut layak dijadikan objek penelitian karena merupakan dua oragnisasi besar yang telah memiliki sejarah panjang yang lahir dalam bentuk pemikiran-pemikiran dan perannya dalam mencerahkan kehidupan beragama, mencerdaskan dan menyadarkan umat serta meningkatkan harkat dan martabat bangsa. Disisi lain kedua organisasi Islam tersebut memiliki ciri khas tersendiri dalam menjalankan visi misinya dalam berdakwah.

Muhammadiyah dalam berdakwah diwujudkan dengan mengaktualisasikan ajaran-ajaran Islam ke dalam kehidupan yang konkret dengan membangun sekolah guru, mendirikan balai kesehatan, memelihara anak yatim, memberdayakan orang-orang miskin dengan memelihara, melatih bekerja dan mencarikan mereka pekerjaan, mendidik anak-anak dan pemuda-pemuda dalam kepanduan Hizbul Wathan, mendirikan ganisasi wanita dan lain-lain. ${ }^{6}$

Senada dengan Muhammadiyah, Nadhlatul Ulama pada awal berdirinya menitik beratkan perjuangannya di bidang pendidikan berbasis pesantren, dan berupaya mendirikan lembagalembaga sosial dengan mendirikan operasi sebagai salah satu contoh. ${ }^{7}$

Dari berbagai kegiatan yang dilakukan oleh kedua organisasi Islam ini terlihat adanya berbagai aset histori yang wajib diselamatkan oleh pemerintah sebagai

\footnotetext{
${ }^{6}$ Alwi Shihab, Membendung Arus Respon Gerakan Muhammadiyah Terhadap Penetrasi Misi Kristen Di Indonesia, xiii-xiv.

${ }^{7}$ Hilmy Muhammdiyah \& Sulthan Fatoni, $N U$ : Identitas Islam Indonesia, 122.
} 
khazanah perjalanan bangsa. Sebagai bukti keseriusan pemerintah dalam hal ini ANRI (Arsip Nasional Republik Indonesia) menerbitkan Peraturan Kepala Arsip Nasional Republik Indonesia Nomor 7 tahun 2017 tentang Gerakan Nasional Sadar Arsip. Gerakan ini merupakan acuan bagi pencipta arsip baik lembaga maupun organisasi dalam melaksanakan tertib arsip yang diwujudkan melalui aspek kebijakan, organisasi, sumber daya kearsipan, prasarana dan sarana, pengelolaan arsip serta pendanaan kearsipan. ${ }^{8}$

Dengan adanya aturan-aturan kearsipan sebagai payung hukum pengelola arsip di atas, kedua organisasi baik Muhammadiyah dan Nadhlatul Ulama sejak tahun 1995 mulai menertibkan arsipnya dengan menyerahkan penyimpanannya kepada ANRI. Selain itu saat ini mereka mulai memikirkan untuk mengakuisisi arsip histori yang masih tersimpan pada individu-individu para tokoh dari kedua organisasi.

Berdasarkan pemikiran di atas, maka pertanyaan penelitian ini adalah bagaimanakah penyelamatan arsip yang dilakukan Nahdlatul Ulama dan Muhammadiyah sebagai organisasi Islam terbesar dalam melestarikan rekam jejak sejarahnya di Indonesia?

\section{Tujuan dan Manfaat Penelitian}

Tujuan penelitian ini adalah untuk mengetahui upaya penyelamatan arsip yang tercipta di dua organisasi kemasyarakatan Islam terbesar di Indonesia, yakni NU dan Muhammadiyah. Adapun manfaat penelitian ini sebagai berikut:

a. Memberi kontribusi pada masyarakat mengenai khasanah arsip keislaman di

\footnotetext{
${ }^{8}$ Arsip Nasional Republik Indonesia, Peraturan Kepala Arsip Nsaional Republik Indonesia Nomor 7 Tahun 2017 Tentang Gerakan Nasional Sadar Tertib Arsip, 2.
}

Indonesia, dalam hal ini diwakili oleh dua organisasi Islam tersebut di atas;

b.Memberikan informasi upaya penyelamatan arsip organisasi Islam di Indonesia;

c.Menjadi bagian dari sosialisasi program pengembangan kearsipan organisasi.

\section{d. Tinjauan Literatur}

Masyarakat dan organisasi membuat dan menggunakan arsip berhubungan dengan aktivitas atau fungsi bisnis yang berkaitan dengan dirinya. Oleh karenanya arsip dapat dijadikan sebagai alat bukti kegiatan dan antar hubungan (interrelationship). Selain itu arsip sebagai alat informasi yang berkaitan dengan asosiasi masyarakat, organisasi, peristiswa dan tempat kejadian. ${ }^{9}$ Dari pernyataan ini dapat dikatakan bahwa yang dimaksud dengan arsip adalah sesuatu yang tercipta dari organisasi dan kemasyarakatan yang memiliki nilai bagi individu, organisasi atau kemasyarakatan. Atau dapat dikatakan bahwa arsip merupakan sesuatu yang memiliki nilai keberlanjutan (records of continuing). ${ }^{10}$ Arsip yang bernilai seperti inilah yang harus diselamatkan.

Penyelamatan arsip yang bernilai tersebut sebagaimana dinyatakan oleh Ellis (1993) bahwa beberapa arsip dari aktivitas bisnis organisasi dilestarikan dan diselamatkan karena nilai guna keberlanjutan yang dimilikinya, baik menyangkut individu, organisasi dan nantinya akan bernilai guna bagi masyarakat. Beberapa arsip tersebut berfungsi di antaranya adalah:

a.Arsip dijadikan sebagai memori jangka panjang, akses kepada pengalaman

\footnotetext{
${ }^{9}$ Sue McKemmish, Introducing Archives and Archival Programs. Dalam Judith Ellis (Ed.). Keeping Archives, 1.

${ }^{10}$ Sue McKemmish, 18.
} 
yang telah lalu, keahlian dan pengetahuan, serta perspektif sejarah; b.Sebagai sebuah cara untuk mengakses pengalaman orang lain;

c.Sebagai bukti atas hak-hak dan kewajiban yang berkelanjutan;

d.Sebagai instrument kekuatan, legitimasi dan akuntabilitas serta memfasilitasi interaksi dan kohesi sosial;

e.Sebagai sumber pemahaman dan identifikasi diri, organisasi dan masayarakat;

f.Sebagai sarana komunikasi nilai-nilai politik, sosial dan kultural. ${ }^{11}$

Dari pengertian di atas dapat dipahami bahwa arsip yang bernilai kelanjutan yang wajib diselamatkan terdapat pada sebuah organisasi. Organisasi yang dimaksud dalam penelitian ini adalah dua organisasi Islam, Muhammadiyah dan Nadhlatul Ulama.

Nahdlatul Ulama disingkat NU berdiri pada 31 Januari 1926 yang memiliki makna "Kebangkitan Para Ulama". Makna ini bermakna bahwa NU didirikan oleh para ulama pengasuh pondok pesantren yang di dalam komunitas Islam mempunyai kesamaan wawasan, pandangan, sikap dan tatacara pemahaman, penghayatan dan pengamalan ajaran Islam Ahlussunah Wal-Jamaah, yakni sebuah paham yang bersumber pada al-Qur'an, As-Sunnah, Al-Ijma dan ak-Qiyas. ${ }^{12}$

Muhammadiyah didirikan oleh Haji Ahmad Dahlan pada tahun 1912 dikampungnya Kauman, Yogyakarta. Sebagai organisasi pembaharu yang memiliki semboyan gerakan amar ma'ruf nahi munkar kembali kepada Al-Qur'an dan Sunnah (al-ruju ila Al-Qur'an wa Al-Sunnah), Muhammadiyah bergerak dengan membuka sekolah-sekolah yang

\footnotetext{
${ }^{11}$ Judith Ellis, Keeping Archives.

${ }^{12}$ Kacung Marijan, Quo Vadis NU; Setelah Kembali Ke Khittah 1926.
}

bertujuan mengubah mindset masyarakat saat dengan dengan tindakan nyata yakni dengan mendirikan amal usaha. Konsep ini berakar dari pemikiran KH. Ahmad Dahlan yang mengajarkan untuk berbuat bukan berpikir. ${ }^{13}$

Sejauh ini penulis tidak mendapatkan kajian terdahulu mengenai penyelamatan arsip sejarah organisasi kemasyarakatan Islam. Penelitian terkait hanya menyangkut penyelamatan arsip negara dan sub-unit kerja perguruan tinggi.

\section{Metodologi Penelitian}

Tulisan ini didasari pada penelitian penulis yang menggunakan pendekatan kualitatif yang berangkat dari masalah untuk melihat fenomena secara lebih luas dan mendalam sesuai apa yang terjadi dan berkembang pada situasi sosial yang diteliti. ${ }^{14}$ Metode yang digunakan adalah studi kasus, di mana peneliti menyelidiki secara cermat suatu program, peristiswa, aktivitas, proses atau sekelompok individu. ${ }^{15}$

Pengumpulan data dilakukan dengan cara observasi, wawancara semi terstruktur dengan beberapa manager arsip atau pengelola arsip di kantor Gedung Dakwah Pimpinan Pusat Muhammadiyah Jakarta dan kantor Pimpinan Besar Nahdlatul Ulama di Jakarta, sertra para tokoh yang memiliki wewenang dalam merumuskan kebijakan dalam pengelolaan arsip statis di kedua organisasi tersebut. Penulis melaksanakn kegiatan riset di Jakarta dengan mempertimbangkan bahwa kegiatan pengelolaan arsip secara khusus banyak dilakukan di kantor sekretariat yang berada di Jakarta sebagai pusat organisasi atau perwakilannya. Para

${ }^{13}$ Alwi Shihab, Membendung Arus Respon Gerakan Muhammadiyah Terhadap Penetrasi Misi Kristen Di Indonesia.

\footnotetext{
${ }^{14}$ Sugiono, Metode Peneliian Manajemen, 349.

${ }^{15}$ Creswell, Research Design Pendekatan Kualitatif, Kuantitatif, dan Mixed.
} 
informan juga beraktivitas pada kantor tersebut. Selain itu penulis juga mewawancarai tokoh-tokoh pada organisasi NU maupun Muhammadiyah yang dinilai memiliki gagasan dan gerakan nyata, baik secara individu maupun secara organisatoris, dalam kegiatan penyelamatan arsip penting organisasinya. Dalam melakukan wawancara ini peneliti mendengarkan secara teliti dan mencatat apa yang dikemukakan informan. ${ }^{16}$

Dalam menganalisa dan menyajikan data, peneliti melakukan pengolahan data, membaca keseluruhan dan mencatat data yang diperoleh, menganalisi dengan memberikan kode, melakukan penarikan kesimpulan, mengkaji literatur dan membuat kesimpulan, saat data dilapangan sudah mencapai titik jenuh. ${ }^{17}$

\section{B. Pembahasan}

1. NU dan Muhammadiyah; Aktivitas dan Jenis Arsip yang dihasilkannya

Gerak laju organisasi

kemasyarakatan Islam di Indonesia merupakan sebuah fenomena menarik dan penting untuk dikaji, mengingat nahwa hal ini merepresentasikan kondisi mayoritas masyarakat muslim di Indonesia. Organisasi Islam dalam dinamikanya menjadi kekuatan sosial politik yang diperhitungkan. Dari kajian aspek sejarah, kehadirannya merupakan sebuah aset dasar dalam perubahan negara dan bangsa bersama lahirnya berbagai organisasi lainnya seperti Syarikat islam, Syarikat Dagang Islam, dan lain-lain yang berjuang bersama sejak masa pra-kemerdekaaan.

Lahirnya organisasi Islam tidak lepas dari peran para ulama, seperti misalnya KH. Ahmad Dahlan dan

\footnotetext{
${ }^{16}$ Sugiono, Metode Peneliian Manajemen.

${ }^{17}$ Creswell, Research Design Pendekatan Kualitatif, Kuantitatif, Dan Mixed.
}

KH. Fahruddin sebagai tokoh pendiri Muhammadiyah dan KH. Hasyim Asy'ari sebagai pendiri Nahdlatul Ulama. Kedua organisasi Islam ini memiliki kesamaan yang cukup besar yakni melakukan pembaharuanpembaharuan untuk kembali kepada AlQur'an dan As-Sunnah. Caranya adalah dengan mendirikan dan memajukan lembaga pendidikan agama, memahami pengertian agama dan hidup berdasarkan agama.

Dengan demikian maka dalam memahami organisasi Islam dan arsipnya, maka tidak terlepas dari sejarah pendiri tokohnya, pemikirannya serta hasil produk kegiatannya. Dalam bab "Getting Organised", AnneMarie Schwirtlich menyatakan bahwa archives are those records of social and organisational activity preserve because of their continuing value. ${ }^{18}$ Jadi arsip aktivitas organisasi kemasyarakatan yang harus diperhatikan dengan sangat seksama pelestarian dan keselematannya adalah yang mempunyai nilai kontinuitas (keberlangsungan). Hal ini dapat digambarkan sebagai produkproduk arsip yang tercipta (dibuat atau diterima) sebagai bukti keberadaan dari organisasi ini.

Sampai akhir tahun 2000, jaringan organisasi Nahdlatul Ulama (NU) meliputi: 31 Pengurus Wilayah, 339 Pengurus Cabang, 12 Pengurus Cabang Istimewa, 2.630 Majelis Wakil Cabang dan 37.125 Pengurus Ranting. ${ }^{19}$ Selain itu dalam tubuh NU juga terdapat 18 lembaga sebagai perangkat departementasi organisasi NU yang berfungsi sebagai pelaksana kebijakan NU, berkaitan dengan kelompok masyarakat tertentu dan/atau yang memerlukan penanganan khusus. Lembaga-lembaga tersebut adalah :

- Lembaga Dakwah Nahdlatul

\footnotetext{
${ }^{18}$ Judith Ellis, Keeping Archives.

${ }^{19}$ Nahdlatul Ulama, "Jaringan," 1.
} 
Ulama (LDNU), yang bertugas melaksanakan kebijakan NU di bidang pengembangan agama Islam yang menganut faham Ahlussunnah wal Jamaah.

- Lembaga Pendidikan Maarif Nahdlatul Ulama (LP Maarif NU) yang bertugas melaksanakan kebijakan NU di bidang pendidikan dan pengajaran formal.

- Rabithah Ma'ahid al Islamiyah Nahdlatul Ulama disingkat RMI NU, bertugas melaksanakan kebijakan Nahdlatul Ulama dibidang pengembangan pondok pesantren dan pendidikan keagamaan.

- Lembaga Perekonomian Nahdlatul Ulama (LPNU) bertugas melaksanakan kebijakan NU di bidang pengembangan ekonomi warga NU.

- Lembaga Pengembangan Pertanian Nahdlatul Ulama disingkat LPPNU, bertugas melaksanakan kebijakan NU di bidang pengembangan dan pengelolaan pertanian, kehutanan dan lingkungan hidup.

- Lembaga Kemaslahatan Keluarga Nahdlatul Ulama (LKKNU), bertugas melaksanakan kebijakan NU di bidang kesejahteraan keluarga, sosial dan kependudukan.

- Lembaga Kajian dan Pengembangan Sumberdaya Manusia Nahdlatul Ulama disingkat LAKPESDAM NU, bertugas melaksanakan kebijakan NU di bidang pengkajian dan pengembangan sumber daya manusia.।

- Lembaga Penyuluhan dan Bantuan Hukum Nahdlatul Ulama disingkat LPBHNU, bertugas melaksanakan pendampingan, penyuluhan, konsultasi, dan kajian kebijakan hukum.

- Lembaga Seni Budaya Muslimin Indonesia NU (LESBUMI NU), bertugas melaksanakan kebijakan Nahdlatul Ulama di bidang pengembangan seni dan budaya.

- Lembaga Amil Zakat, Infaq dan Shadaqah NU disingkat LAZISNU, bertugas menghimpun, mengelola dan mentasharufkan zakat dan shadaqah kepada mustahiqnya.

- Lembaga Waqaf dan Pertanahan NU disingkat LWPNU, bertugas mengurus, mengelola serta mengembangkan tanah dan bangunan serta harta benda wakaf lainnya milik NU.

- Lembaga Bahtsul Masail Nahdlatul Ulama disingkat LBMNU, bertugas membahas masalah-masalah maudlu'iyah (tematik) dan waqi'iyah (aktual) yang akan menjadi Keputusan Pengurus Besar NU.

- Lembaga Ta'mir Masjid Nahdlatul Ulama disingkat LTMNU, bertugas melaksanakan kebijakan NU di bidang pengembangan dan pemberdayaan Masjid.

- Lembaga Kesehatan Nahdlatul Ulama disingkat LKNU, bertugas melaksanakan kebijakan NU di bidang kesehatan.

- Lembaga Falakiyah Nahdlatul Ulama disingkat LFNU, bertugas mengelola masalah ru'yah, hisab dan pengembangan ilmu falak.

- Lembaga Ta'lif wan Nasyr Nahdlatul Ulama disingkat LTNNU, bertugas mengembangkan penulisan, penerjemahan dan penerbitan kitab/ buku serta media informasi menurut faham Ahlussunnah wal Jamaah.

- Lembaga Pendidikan 
Tinggi Nahdlatul Ulama disingkat LPTNU, bertugas mengembangkan pendidikan tinggi NU.

- Lembaga Penanggulangan Bencana dan Perubahan Iklim Nahdlatul Ulama disingkat LPBI NU, bertugas melaksanakan kebijakan NU dalam pencegahan dan penanggulangan bencana serta eksplorasi kelautan. ${ }^{20}$

Selain itu dalam struktur organisasi NU juga terdapat Badan Otonom yakni perangkat organisasi NU yang berfungsi melaksanakan kebijakan NU yang berkaitan dengan kelompok masyarakat tertentu dan beranggotakan perorangan. Badan Otonom dikelompokkan dalam kategori Badan Otonom berbasis usia dan kelompok masyarakat tertentu, dan Badan Otonom berbasis profesi dan kekhususan lainnya. Badan otonom yang pertama sangat dikenal masyarakat dengan berbagai kiprah gerakannya yang bersifat strategis. Jenis Badan Otonom berdasarkan kelompok usia dan kelompok masyarakat tertentu tersebut adalah:

- Muslimat Nahdlatul Ulama disingkat Muslimat NU untuk anggota perempuan NU.

- Fatayat Nahdlatul Ulama disingkat Fatayat NU untuk anggota perempuan muda NU berusia maksimal 40 (empat puluh) tahun.

- Gerakan Pemuda Ansor Nahdlatul Ulama disingkat GP Ansor NU untuk anggota laki-laki muda NU yang maksimal berusia 40 (empat puluh) tahun.

- Ikatan Pelajar Nahdlatul Ulama disingkat IPNU untuk pelajar dan santri laki-laki NU yang maksimal berusia 27 (dua puluh tujuh) tahun.।

\footnotetext{
${ }^{20}$ Nahdlatul Ulama, "Lembaga,” 1.
}

- Ikatan Pelajar Putri Nahdlatul Ulama disingkat IPPNU untuk pelajar dan santri perempuan Nahdlatul Ulama yang maksimal berusia 27 (dua puluh tujuh) tahun.

- Pergerakan Mahasiswa Islam Indonesia disingkat PMII untuk mahasiswa Nahdlatul Ulama yang maksimal berusia 30 (tiga puluh) tahun. 21

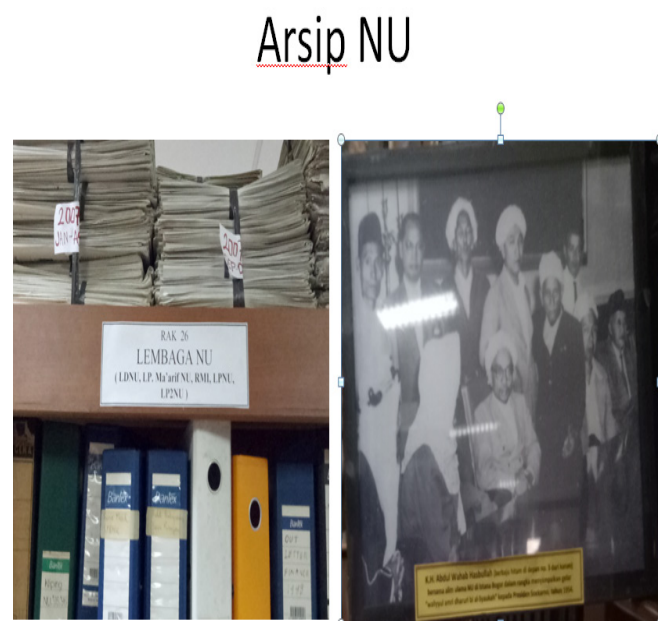

Sumber: Dokumen/ Arsip Koleksi Perpustakaan PBNU

Jenis badan otonom berbasis profesi dan kekhususan lainnya juga terstruktur pada organisasi NU yakni: Jam'iyyah Ahli Thariqah Al-Mu'tabarah An-Nahdliyyah disingkat JATMAN untuk anggota NU pengamal tharekat yang mu'tabar; Jam'iyyatul Qurra Wal Huffazh disingkat JQH, untuk anggota NU yang berprofesi Qori/Qoriah dan Hafizh/ Hafizhah; Ikatan Sarjana Nahdlalul Ulama disingkat ISNU adalah Badan Otonom yang berfungsi membantu melaksanakan kebijakan NU pada kelompok sarjana dan kaum intelektual; Serikat Buruh Muslimin Indonesia disingkat SARBUMUSI untuk anggota NU yang berprofesi sebagai buruh/karyawan/tenaga kerja; Pagar Nusa untuk anggota Nahdlatul Ulama yang bergerak pada pengembangan seni

\footnotetext{
${ }^{21}$ Nahdlatul Ulama, "Badan Otonom," 1.
} 
bela diri; Persatuan Guru Nahdlatul Ulama disingkat PERGUNU untuk anggota NU yang berprofesi sebagai guru dan atau ustadz; Serikat Nelayan Nahdlatul Ulama untuk anggota NU yang berprofesi sebagai nelayan; dan Ikatan Seni Hadrah Indonesia Nahdaltul Ulama disingkat ISHARINU untuk anggota NU yang bergerak dalam pengembangan seni hadrah dan shalawat. ${ }^{22}$

Arsip yang tercipta dalam organisasi dapat timbul dalam berbagai media seperti kertas, bentuk mikro, film, pita magnetik, video, ataupun rekaman suara, dalam bentuk surat, file kertas, register, peta, foto, kaset video, pangkalan data terkomputerisasi dan surat elektronik. ${ }^{23}$

Pada organisasi Muahmmadiyah terdapat beberapa majelis pembantu pimpinan persyarikatan yakni: Majelis Tarjih dan Tajdid, Majelis Tabligh, Majelis Pendidikan Tinggi, Majelis Pendidikan Dasar dan Menengah, Majelis Pendidikan Kader, Majelis Pelayanan Sosial, Majelis Ekonomi dan Kewirausahaan, Majelis Pemberdayaan Masyarakat, Majelis Pembina Kesehatan Umum, Majelis Pustaka dan Informasi, Majelis Lingkungan Hidup, Majelis Hukum Dan Hak Asasi Manusia, Majelis Wakaf dan Kehartabendaan. ${ }^{24}$ Selain itu juga terdapat beberapa lembaga yakni:

- Lembaga Pengembangan Cabang dan Ranting

- Lembaga Pembina dan Pengawasan Keuangan

- Lembaga Penelitian Pengembangan

\footnotetext{
${ }^{22}$ Nahdlatul Ulama, "Badan Otonom."

${ }^{23}$ Sue McKemmish, Introducing Archives and Archival Programs. Dalam Judith Ellis (Ed.). Keeping Archives.

${ }^{24}$ Pimpinan Pusat Muhammdiyah, "Struktur Organisasi," 1.
}

- Lembaga Penanganan Bencana

- Lembaga Zakat Infaq dan Shodaqqoh

- Lembaga Hikmah dan Kebijakan Publik

- Lembaga Seni Budaya dan Olahraga

- Lembaga Hubungan dan Kerjasama International ${ }^{25}$

DalamorganisaiMuhammadiyah juga terdapat beberapa organisasi otonom dengan bebragai aktivitas dan cakupan kerja yakni: Aisyiah, Ikatan Pelajar Muahmmadiyah (IPM), Ikatan Mahasiswa Muhammadiyah (IMM), Hizbul Wathan, tapak Suci, Pemuda Muhammadiyah dan Nasyiatul Aisyiah (NA). Muhammadiyah juang memiliki beberapa jenis amal usaha di bidang pensisikan, rumah sakit dan sosial.

Berbagai lembaga/unit yang terdapat pada organisasi di atas, akan terlihat arsip yang diasumsikan bernilai sejarah. Namun disisi lain. perhatian masyarakat terhadap arsipnya sendiri hingga komitmen untuk menyelamatkan arsip organisasi dan berujung pada terpeliharanya arsip negara masih merupakan pekerjaan rumah yang belum selesai.

Kalangan organisasi kemasyarakatan misalnya, arsip sejarah tokoh-tokoh penting dan karya-karyanya disinyalir masih tersebar dan belum terakuisisi dan terpeihara dengan baik. Hal ini harus segera ditindaklanjuti karena dalam khasanah arsip itulah dapat dikenali dan dikonstruksi kembali sejarah kemajuan umat Islam melalui organisasi kemasyarakatannya. Organisasi yang ingin memajukan kehidupan umat dan bagsanya memerlukan arsip sebagai bahan dalam mengambil keputusan dan bukti akuntabilitas gerakannya.

\footnotetext{
${ }^{25}$ Pimpinan Pusat Muhammdiyah, "Struktur Organisasi."
} 


\section{Pelestarian Arsip di Nahdlatul Ulama} dan Muhammadiyah

Dalam mengkaji penyelamatan arsip, peneliti mengacu pada pendapat yang dikemukakan oeh Anne-Marie Schwirtlich, dimana disebutkan bahwa hal yang terpenting dalam merancang kebijakan arsip dengan menjawab 3 pertanyaan, yakni, berkenaan dengan pengembangan kebijakan, keaslian dari arsip dan pengembangan sumber daya kearsipan sebagai tonggak berjalannya program penyelamatan arsip ${ }^{26}$

1).Pengembangan Kebijakan, Rencana dan Prosedur Program Arsip

Kebijakan penyelamatan arsip statis Muhammadiyah telah dimulai sejak adanya kesepakatan kerjasama antara Pimpinan Pusat Muhammdiyah dengan ANRI sejak tahun 1995. Sejak itu ANRI telah menyimpan ribuan arsip milik Muhammadiyah berupa surat keputusan, foto kegiatan tokoh Muhammadiyah, himbauan dan lain-lain yang pernah dikeluarkan PP Muhammadiyah sejak tahun $1912-1989$.

Pada MoU tahun 2012 kesepakatan diperluas hingga mencakup pembinaan sistem pengelolaan arsip, akuisisi arsip, preservasi arsip, akses arsip, dan kegiatan-kegiatan lain yang disepakati oleh ke dua pihak selama tiga tahun. Melalui MoU ini dapat menambah khazanah arsip Muhammadiyah periode 1912 - 2012 sehingga memungkinkan masyarakat umum dapat mengetahui peranan tokoh Muhammadiyah terdahulu melalui akses arsip kemuhammadiyahan di layanan arsip ANRI. ${ }^{27}$

Secara internal arsip statis Muhammadiyah juga dikelola secara khusus dalam sebuah lembaga yang

\footnotetext{
${ }^{26}$ Judith Ellis, Keeping Archives.

${ }^{27}$ Arsip Nasional Republik Indonesia, "MoU ANRI Dengan PP Muhammadiyah Akan Laksanakan Pengarsipan Arsip Kuno Dan Modern Milik Muhammadiyah.”
}

relatif baru berdiri yakni di Pusat Studi Muhammadiyah dan Museum Muhammadiyah, yang bertempat di Universitas Muhammadiyah Yogyakarta (UMY) yang berfungsi sebagai pusat repositori Muhammadiyah. Selain itu arsip publik kemuhammadiyahan juga diakuisisi di Pimpinan Pusat (PP) Muhammadiyah, baik di Yogyakarta maupun Gedung Dakwah Muhammadiyah di Jakarta. Pada ormas ini arsip dikelola dan dilayankan oleh unit layanan perpustakaan. Perpustakaan secara khusus mengakuisisi arsip berupa terbitan Muhammadiyah dalam berbagai bentuk.

Secara struktural organisasi ini memiliki bidang khusus yang menangani pengembangan layanan informasi dan pustaka yakni Majelis Pustaka dan Informasi, yang dikembangkan dari tingkat pusat hingga daerah pada tingkat Kabupaten/Kota. Majelis ini memiliki beragam program kerja yang cukup komprehensif di bidang kearsipan, khususnya melalui Divisi Museum dan Kearsipan.

Beberapa kegiatan tersebut antara lain adalah penguatan aktivitas digitalisasi arsip dan dokumen Muhammadiyah; penataan sistem dokumentasi dan pengarsipan terhadap berbagai karya, baik internal dan eksternal; penyusunan panduan pengelolaan arsip statis dan dinamis persyarikatan; penyusunan desain dan pengelolaan museum Muhammadiyah; kajian dan bedah arsip muktamar dari masa ke masa; pendampingan pengelolaan arsip di Kantor PWM oleh kantor Arsip di Propinsi; penelusuran arsip persyarikatan; penyerahan arsip statis secara berkala ke ANRI; pendirian museum/ memorabilia atau pusat informasiMuhammadiyah;pembaharuan nota kesepahaman dan perjanjian kerjasama antara Muhammadiyah dengan ANRI; penyediaan database 
kemuhammadiyahan; mendirikan dan mengembangkan Muhammadiyah corner; serta menggiatkan penulisan sejarah lokal Muhammadiyah ${ }^{28}$

Pada ormas NU kebijakan penyelamatan arsip didasari pada $\mathrm{MoU}$ antara PBNU dan ANRI. PBNU pada tahun 2014 telah menyerahkan arsip statis sebanyak 47 boks arsip NU. Salah satu subjek yang diserahkan adalah arsip tentang Gus Dur, baik dalam kapasitasnya sebagai Presiden RI ke-4 maupun sebagai tokoh NU. Arsip NU kini tengah ditingkatkan menjadi arsip inventaris. Dengan kelengkapan, kerapian katalog, dan klasifikasi, peran penting kesejarahan NU tampak utuh bagi mereka yang menulis NU.

Secara struktural, pada organisasi NU terdapat lembaga kajian dan Pengembangan SDM NU (Lakpesdam NU) yang bertugas melaksanakan kebijakan NU di bidang pengkajian dan pengembangan SDM. Sejak tahun 1983 Lakpesdam bertugas mengumpulkan semua arsip tentang ke-NUan, yang didasari keprihatinan para kyai NU terhadap penyelamatan data NU, khususnya kitab-kitab yang digunakan dalam bahtsul masail dalam musyawarah nasional atau pun kongres besar NU. Dengan demikian perpustakaan NU dalam melakukan penyelamatan dokumen primer berupa buku, hasil rapat pleno, hasil ketetapan muktmar, hasil ketetapan Munas -Konbes atau karya tulis ilmiah perihal NU. Selain itu diakuisi pula arsip berupa rekaman audio, video, kalender, termasuk terbitan berkala $\mathrm{NU}^{29}$

\section{2). Program Arsip}

Sebelum dicanangkannya Gerakan Nasional Sadar Terbit Arsip oleh

\footnotetext{
${ }^{28}$ Muhammadiyah, "Jabaran Program MPI 2015-2020."

${ }^{29}$ Nahdatul Ulama, "Melongok Perpustakaan PBNU."
}

ANRI, kedua organisasi Islam ini telah melaksanakan program kearsipan dalam rangka penyelamatan arsip organisasi massa Islam bagi kepentingan bangsa.

\section{3). Arsip Nasional}

Menyelamatkan arsip atau dokumendokumen penting milik organisasi Muhammadiyah mulai 1922-2001 yang diharapkan menjadi referensi kajian dan penelitian bagi generasi mendatang terhadap salah satu organisasi Islam terbesar itu. ${ }^{30}$ Dokumen tersebut sangat bermanfaat bagi para peneliti, mahasiswa dan masyarakat umum sebagai sumber primer di ANRI tentang sejarah Muhammadiyah. Kepala Deputi Konservasi Arsip Nasional RI (ANRI) M. Taufik, mengatakan pengelolaan dokumen atau arsip yang akurat sangat penting untuk menghindari penyesatan informasi di masa mendatang tentang sepak terjang Muhammadiyah. ${ }^{31}$

Arsip statis berupa terbitan Muhammadiyah seperti Majalah Suara Muhammadiyah, hasil penelitian tentang organisasi Muhammadiyah dan tokohnya, hasil keputusan Tanfidz Muktamar, Berita Resmi Muhammadiyah, dan lainnya, yang jumlahnya telah mencapai lebih dari 1300 judul dokumen, di antaranya Tafsir Sinar yang terbit tahun 1966, dan terbitan lain sejak 1930, diakusisi dengan dukungan peraturan deposit sehingga perpustakaan dapat memastikan tersedianya literatur tentang Muhammadiyah untuk keperluan penelitian.

\footnotetext{
${ }^{30}$ Lince Eppang, “Arsip Muhammadiyah Diselamatkan Agar Tidak Ada Penyesatan Informasi Di Masa Depan."

${ }^{31}$ Lince Eppang.
} 
Arsip Muhammadivah
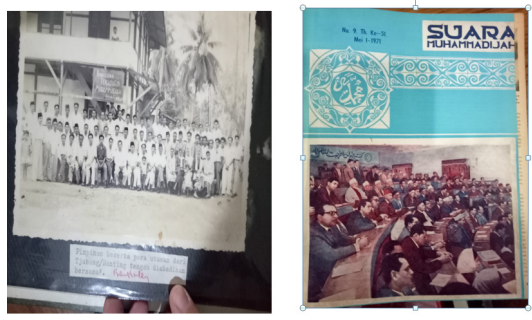

Sumber: Dokumen/ Arsip Perpustakaan

Gedung Dakwah Muhammadiyah

Beberapa terbitan diketahui hanya dapat ditemukan di luarnegeri. Pengelola perpustakaan juga aktif membeli buku terbaru tentang Muhammadiyah. Sebagaimana disebutkan di atas, unit Majelis Pustaka dan Informasi bertanggungjawab atas pengelolaan arsip dan layanan informasi, serta berwenang menyerahkan arsip statis organisasi ini untuk dikelola oleh negara.

Salah satu arsip penting yang penulis temukan di lokus penelitian berupa foto-foto kegiatan organisasi. Arsip foto di organisasi Muhammadiyah masih tersimpan dalam album sedangkan di PBNU sebagian arsip foto sudah berupa hasil reproduksi yang dipajang dalam figura. Arsip jenis ini sangat penting untuk segera diolah sesuai standar kerasipan, terutama untuk mendokumentasikan metadata arsip dengan benar.

Selain informasi yang dilekatkan pada foto, dibutuhkan pula pengetahuan pengelola arsip atau informan yang memahami konteks sejarah terciptanya arsip tersebut. Hal ini sesuai dengan temuan lapangan pada penelitian yang dilakukan oleh Arif menyangkut pengelolaan arsip foto asrama Ratnaningsih UGM, bahwa kerja pengarsipan terkait dengan intellectual handling yang dimiliki individu pengelola arsip, di mana keterbatasan ini dapat menyebabkan kesalahan tafsir dalam menata arsip foto akibat ketidaktahuan terhadap tokoh-tokoh penting yang terekam dalam sebuah arsip foto. ${ }^{32}$

Upaya pelestarian fisik dan isi kandungan arsip di ke dua organisasi sampai saat ini masih minim yakni hanya berupa pembersihan dan perbaikan. Arsip yang berusia tua dan langka masih disimpan bersama arsip lainnya, sehingga dikhawatirkan akan rusak. Muhammadiyah berencana melakukan digitalisasi dengan dukungan SDM yang lebih profesional. Adapun akses arsip statis kemuhammadiyahan di ANRI terbuka secara untuk umum, namun disesuaikan dnegan peraturan Undangundang Informasi Publik.

Kondisi fisik arsip Muhammadiyah pada umumnya baik, namun ditemukan juga arsip yang kondisinya rusak, sebagian karena sobek dan sebagian lainnya karena serangga, ada pula arsip yang susah dibaca karena tintanya sudah terlalu tipis di atas kertas yang juga termasakn usia. Sebagian karena sobek dan sebagian lainnya karena serangga, ada pula arsip yang susah dibaca karena tintanya terlalu tipis. Selanjutnya arsiparsip tersebut akan diolah dengan dilengkapi informasinya meliputi penelusuran sumber dan referensi arsip serta rekonstruksi arsip. ${ }^{33}$

Arsip statis NU yang telah diakuisisi di perpustakaan PBNU maupun ANRI dilayankan bagi pengguna internal maupun masyarakat luas. Penyerahan arsip statis periode 1983 telah dilakukan pada tahun 2014 berdasarkan MoU dengan ANRI. Arsip NU di lembaga kearsipan negara ini dirawat secara khusus. Arsip tersimpan di ruangan

\footnotetext{
${ }^{32}$ Arif Rahman Bramantya, “Jejak Organisasi Asrama Ratnaningsih: Digitalisasi Sebagai Upaya Penyelamatan Arsip,” 30.

${ }^{33}$ Lince Eppang, “Arsip Muhammadiyah Diselamatkan Agar Tidak Ada Penyesatan Informasi Di Masa Depan.”
} 
dengan kadar suhu pendingin stabil antara 18-22 derajat.

Kesepakatan ini juga menyangkut pembinaan kearsipan oleh ANRI. Nina (2017) menyatakan "pengelolaan arsip dilakukan dalam kordinasi Perpustakaan PBNU yang bertempat di Kantor PBNU Jakarta Pusat. Program ini sudah melangkah pada program digitalisasi. Program digitalisasi sudah menjadi kebutuhan mendasar dalam merawat koleksi di Perpustakaan $P B N U . " 34$ Selanjutnya arsip statis NU yang sudah dialihmediakan dalam bentuk digital dapat diakses melalui situs NU Online.

Demikian halnya NU berambisi terus melakukan upaya akuisisi arsip hasil penelitian tentang NU dari penelitian yang berasal dari dalam dan luar negeri. Arsip NU yang telah diserahkan ke ANRI berisi lengkap dokumen muktamar, pertemuan alim-ulama, sidang pleno, administrasi keanggotaan, catatan keuangan, kepengurusan, dan badan otonom dan lembaga NU. Berkas arsip NU juga memuat informasi amal usaha dan peran NU terkait pendidikan, ekonomi, politik, sosial, ketenagakerjaan, keamanan, pertahanan, dan hubungan luar negeri baik pada masa penjajahan Belanda, Jepang, masa Revolusi hingga masa kemerdekaan $\mathrm{RI}^{35}$

NU juga telah berhasil mengumpulkan arsip NU secara optimal yang digagas dan dimotori oleh Kyai Mun'im DZ, Sekjen PBNU. Dengan pembenahan ini pada tahun 2014 lalu NU mendapat anugrah "Ormas dengan Penataan Arsip Paling Lengkap dan Rapi" yang diberikan oleh Kantor ARSIP Nasional (ANRI). Dengan pengabdiannya beliau

34Nina, "Wawancara Dengan Kepala Perpustakaan Pengurus Besar Nahdatul Ulama."

${ }^{35}$ Alhafiz K, "PBNU Pantau Pengolahan Arsip NU Di ANRI." kemudian mendapatkan apresiasi dan diminta untuk menjadi salah satu tokoh pengarah dan pembina penataan Arsip Nasional. Hal ini merupakan wujud nyata pelaksanaan PP No. 28 tahun 2012 pasal (66) yang menyebutkan bahwa Pemerintah dapat memberikan penghargaan kepada anggota masyarakat. ${ }^{36}$

Kalangan intelektual muda Muhammadiyah muncul tokoh Dr. Sudarnoto Abdul Hakim, yang merupakan akademisi di bidang sejarah Islam yang sejak beberapa tahun lalu telah mengambil peran penting dalam penyelamatan arsip Muhammadiyah. Sudarnoto melakukan beberapa upaya meliputin penelusuran, pengumpulan naskah, tulisan, dan catatan lama tentang sebuah ayat atau terjemahan dan penjelasan dari tulisan yang dibuat oleh tokoh Muhammadiyah khususnya para pendiri, dan guru-guru Muhammadiyah agar tak hilang ditelan zaman. Arsip ini menunjukkan bukti bahwa para guru, mbah-mbah Muhammadiyah merupakan intelektual Islam. Sebagian catatan itu sudah dicetak. Hal itu membuktikan bahwa mereka pun sadar akan bentuk publikasi tentang keilmuan.

Dalam menerapkan program penyelamatan arsip di lapangan ke dua organisasi Islam ini masih banyak menemui kendala dan tantangan. Tantangan terbesar dari penyelamatan arsip organisasi Islam adalah masih tersimpannya arsip secara desentralisasi. Artinya adalah bahwa masih tersimpan arsip organisasi di masing-masing tokoh, kantor wilayah, kantor daerah, kantor cabang, kantor ranting. Hal ini terungkap dari tulisan David Efendy yang menyatakan bahwa "arsip

\footnotetext{
${ }^{36}$ Republik Indonesia, "Peraturan Pemerintah Republik Indonesia Nomor 28 Tahun 2012 Tentang Pelaksanaan Undang-Undang Nomor 43 Tahun 2009 Tentang Kearsipan."
} 
Muhammadiyah masih disimpan oleh person-person atau cabang/ranting/ daerah". ${ }^{37}$

Kalangan aktivis organisasi Muhammadiyah juga telah muncul kesadaran tertib arsip sebagaimana diungkap oleh Sudarnoto dalam pernyataan sebagai berikut: "Semoga arsip Muhammadiyah yang masih disimpan oleh person-person atau cabang/ranting/daerah segera bisa dikumpulkan atau disalin oleh Majelis Pustaka Informasi PP Muhammadiyah sebagai lembaga yang paling otoritatif terkait kearsipan Muhammadiyah. Tahap berikutnya segera diserahkan ke ANRI agar bisa diolah dan dirawat dengan baik, juga tentunya bisa diakses oleh siapapun yang ingin tahu tentang perjalanan Muhammadiyah sejak 1912." 38

Secara kelembagaan, dari kalangan NU dinyatakan pula bahwa penyelamatan arsip khususnya baru dimulai pada masa kepemimpinan alm Hasyim Muzadi. Hingga saat ini NU terus bebenah diri mengumpulkan arsip terkait sejarah organisasi, tokoh-tokoh dan karyakarya para civitasnya termasuk literatur manuskrip berupa berisi teks shalawat karya para ulama terdahulu yang tersebar di berbagai pesantren ${ }^{39}$.

Muhammadiyah sebagai organisasi kemasyarakatan Islam yang dikenal modern dan memegang teguh karakter berkemajuan mensyaratkan gerakan keilmuwan yang sangat kuat yang ditopang oleh tradisi riset, dokumentasi, arsip, yang itu bermuara pada produksi dan reproduksi ilmu pengetahuan dan teknologi untuk

\footnotetext{
${ }^{37}$ David Efendi, “Tantangan Pengeloaan Arsip Muhammadiyah."

${ }^{38}$ David Efendi.

${ }^{39}$ Mastur, "Wawancara Dengan Sekretaris PBNU."
}

sebesar besarnya kehidupan manusia. ${ }^{40}$ Untuk itu secara struktural organisasi ini memiliki bidang khusus yang menangani pengembangannya yakni Bidang Pustaka dan Informasi, yang dikembangkan dari tingkat pusat hingga daerah di kabupaten/ kota.

Sebagian arsip penting sejak masa awal NU berdiri masih tersimpan di perpustakaan di Gresik yang menjadi rujukan peneliti internasional dalam membuat laporan penelitian tentang NU (Arsip NU Menuju Digitalisasi). Pada 2014 NU juga telah menyerahkan arsip periode 1952-1982 untuk dititipkan kepada ANRI dan hanya boleh dibuka jika ada izin dari PBNU. Meskipun hal ini tampak sebagai pembatasan akses namun hal ini sesuai dengan pasal (66) UU Kearsipan No. 43 tahun 2009 yang memungkinkan akses arsip berdsarkan persetujuan dari pimpinan pencipta arsip. $^{41}$

\section{3). Manajemen Sumber daya Manusia}

Baik di organisasi NU maupun Muhammadiyah arsip statis dikelola dan dilayankan oleh staf perpustakaan, baik yang berkualifikasi pendidikan ilmu perpustakaan dan informasi maupun pelatihan kearsipan, yang didukung oleh staf administrasi. Keterbatasan SDM kearsipan ini memang merupakan masalah yang sangat mendasar, baik di lembaga pemerintah maupun nonpemerintah.

Penyelamatan arsip di organisasi Islam mengalami beberapa masalah. David $^{42}$ mengidentifikasi tantangan utama di organisasi Muhammadiyah,

\footnotetext{
${ }^{40}$ David Efendi, "Tantangan Pengeloaan Arsip Muhammadiyah."

${ }^{41}$ Republik Indonesia, "Peraturan Pemerintah Republik Indonesia Nomor 28 Tahun 2012 Tentang Pelaksanaan Undang-Undang Nomor 43 Tahun 2009 Tentang Kearsipan."

${ }^{42}$ David Efendi, "Tantangan Pengeloaan Arsip Muhammadiyah."
} 
yakni tantangan mentalitas kearsipan. Pada tataran pimpinan dan warga masih belum cukup menghargai arsip. Kesadaran ini diperlukan karena akan menjadikan arsip bermakna, mendukung riset, dan juga mendukung kultur literasi dan akses informasi tentang Muhammadiyah bagi kalangan masyarakat luas baik dalam maupun luar negeri.

Sudarnoto menegaskan bahwa meskipun usaha pengarsipan dan perawatan naskah sudah menjadi tugas Negara, akan tetapi keterlibatan individu yang sadar juga dibutuhkan ketika tradisi arsip belum menjadi kultur masyarakat. Naskah lama, tulisan-tulisan tentang Islam, yang dibuat oleh mbah-mbah Muhammadiyah banyak yang belum dibukukan, yang sebagian besar juga masih berupa tulisan tangan yang ditulis dalam lembaran lepas. Sebagian besar tulisan itu berbahasa Jawa dan ditulis dengan huruf Latin, bahkan juga ada yang menggunakan huruf Arab yang dikenal sebagai Arab Jawi. ${ }^{43}$

Beberapa bentuk arsip organisasi kemasyarakatan Islam menunjukkan pemikiran para tokoh Islam yang amat luas, terbuka, dan maju. Meskipun mereka menuliskan catatan tersebut awalnya mungkin hanya untuk tujuan mengajarkan Islam kepada murid-murid mereka, seperti sebagian besar tafsir Jus Amma, naskah terjemahan hingga naskah yang berbicara soal peradaban dan cara membangun peradaban bangsa. Ada catatan tentang perjalanan negeri ini dan komentar mereka tentang peristiwa yang terjadi ketika itu. Ada juga tentang catatan pengajian biasa, tetapi diberikan catatan penting tentang tafsir mereka "Semua itu penting dalam peradaban Islam Indonesia untuk membangun bangsa ini dengan elemen Islam dalam kebangsaannya," jejak para penggerak

${ }^{43}$ Sudarnoto Abdul Hakim, "Merawat Catatan Mbah-Mbah Muhammadiyah."
Persyarikatan Muhammadiyah, yang selalu menularkan nilai universal, bersikap plural, mampu membumikan Islam dengan masyarakat dan budaya setempat, serta diakui di dunia Islam. ${ }^{44}$

Sesuai dengan UU No. 43 tentang Kearsipan, maka ANRI sebagai lembaga kearsipan nasional berkewajiban dan berwenang untuk memelihara dan melayankan arsip statis organisasi kemasyarakatan. Untuk itu organisasi kemasyarakatan Islam harus berperan aktif dalam mendukung hal tersebut.

Peran serta masyarakat dalam penyelamatan arsip diamanatkan dalam Undang-Undang tersebut pada Pasal 71 ayat (2) yang menyebutkan bahwa penyelamatan arsip dilaksanakan dengan cara: a. menyerahkan arsip statis kepada lembaga kearsipan; b. melaporkan kepada lembaga kearsipan apabila mengetahui terjadinya penjualan, pemusnahan, perusakan, pemalsuan, dan pengubahan arsip oleh lembaga negara tanpa melalui prosedur sebagaimana diatur dalam Undang-Undang ini; dan c. melindungi dan menyelamatkan arsip dan tempat penyimpanan arsip dari bencana alam, bencana sosial, perang, sabotase, spionase, dan terorisme melalui koordinasi dengan lembaga terkait. ${ }^{45}$

Selanjutnya pada pasal 77 dinyatakan bahwa organisasi politik, organisasi kemasyarakatan, dan perseorangan menyerahkan arsip statis dari kegiatan yang didanai dari anggaran negara dan/atau bantuan luar negeri kepada lembaga kearsipan sesuai dengan ketentuan peraturan perundangundangan. ${ }^{46}$

Dalam mensosialisasikan arsipnya, Muhammadiyah antara lain ${ }^{44}$ Sudarnoto Abdul Hakim.

45 Republik Indonesia, "UndangUndang Republik Indonesia Nomor 43 Tahun 2009 Tentang Kearsipan." 46 Republik Indonesia. 
juga telah melakukan Pameran Arsip 100 Tahun Muhammadiyah pada 2012 lalu. Pameran yang bertema "Meretas Jejak Muhammadiyah Di Bumi Nusantara" memamerkan khazanah arsip ANRI yang berhubungan dengan perkembangan Muhammadiyah di seluruh wilayah Indonesia. ${ }^{47}$ Kegiatan ini mengungkapkan berbagai kenyataan tentang perkembangan Muhammadiyah yang mungkin selama ini juga tidak seluruhnya terlalu diketahui oleh warga Muhammadiyah.

Demikian halnya ANRI bekerja sama dengan NU menggelar Ekspose Inventaris Arsip NU 1952-1982 pada 2014. Tujuan terselenggaranya kegiatan tersebut diharapkan dapat menjadikan arsip sebagai sumber data, informasi dan pengetahuan. NU mengharapkan untuk menjadikan arsip sebagai sumber data, informasi, pengetahuan, dan kearifan yang dapat memberikan kesejahteraan bagi masyarakat Indonesia dan dunia internasional. Inventaris arsip NU 1952 1982 berisi uraian informasi mengenai tugas dan fungsi NU sebagai organisasi sosial keagamaan maupun politik seperti informasi tentang kesekretariatan, keorganisasian, keagamaan, sosial, perburuhan, pendidikan dan lain-lain.

Khazanah arsip NU yang tersimpan di ANRI banyak dicari oleh pengguna arsip untuk berbagai kepentingan terutama semasa NU masih menjadi partai politik. Untuk memenuhi ketersedian arsip statis NU dilakukan pengaturan informasi dan fisik arsip untuk menghasilkan sarana bantu penemuan kembali arsip (finding aids) berupa Inventaris Arsip NU 1952.

Majelis Pustaka dan Informasi (MPI) PP Muhammadiyah juga melakukan berbagai kegiatan pembinaan tata kelola arsip tingkat pusat, wilayah, maupun daerah, di antaranya dengan

\footnotetext{
${ }^{47}$ Roni Thabroni, "Pameran Arsip Muhammadiyah," 1 .
}

menggelar Pelatihan dan Pengelolaan Arsip Persyarikatan di Pusat Dakwah Muhammadiyah.

Pengelolaan arsip sudah dimulai pada tahun 1995. Perhatian organisasi Muhammadiyah terhadap pentingnya tata kelola arsip mengalami dinamika, ketika Majelis Pustaka PP Muhammadiyah sempat dinonaktifkan. Beberapa tahun kemudian majelis tersebut diaktifkan kembali dengan perubahan namanya Majelis Pustaka dan Informasi. Pada periode kepemimpinan Prof. Din Syamsudin Majelis Pustaka dan Informasi mulai berjalan dengan berbagai pembaharuan untuk kemajuan organisasi.

\section{Kesimpulan}

NU yang dikenal sebagai penjaga tradisi Islam dan Muhammadiyah sebagai organisasi kemasyarakatan Islam modern, keduanya melakukan gerakan keilmuwan maupun aktivitas dakwah sosial melalui berbagai lembaga dan kegiatan. Visi, misi dan aktivitasnya telah dan akan terus menghasilkan arsip yang sangat penting bagi masyarakat nasional maupun global.

Kesadaran akan penyelamatan arsip organisasi massa Islam ini berhulu dari dalam organisasi itu sendiri dan kerjasama dengan ANRI. NU telah memulai upaya ini dengan menyerahkan arsip statis sejak 2014, meskipun upaya internal telah dilakukan sejak 1983, sementara Muhammadiyah telah melakukannya sejak 2012. Secara struktural ke duanya memiliki lembaga khusus yang salah satu tugasnya berkaitan dengan misi ini, masing-masing adalah Lakpesdam NU dan Majelis Pustaka dan Informasi Muhammadiyah. Dengan demikian ormas Islam ini telah menunjukkan perhatian serius dalam penyelamatan arsip keislaman melalui pengembangan kebijakan, rencana dan prosedur program 
kearsipan. Upaya yang dilakukan berupa akuisisi, pembersihan arsip, perbaikan dan merencanakan program digitalisasi. Pada NU program seperti ini sudah berjalan dengan lebih baik, yang dialkukan melalui Perpustakaan PBNU. Dalam aspek SDM kearsipan ormas Islam ini juga didukung oleh SDM bidang Ilmu Perpustakaan dan bidang lain yang mendapat pelatihan kearsipan. Selain itu program penyelamatan arsip ini didukung oleh tokoh-tokoh aktivis dan intelektual.

Sinergi ini diharapkan akan dapat diimplementasikan juga di kalangan organisasi massa Islam lainnya di Indonesia.

\section{Daftar Pustaka}

Alhafiz K. "PBNU Pantau Pengolahan Arsip NU Di ANRI." Nu Online, 2014. PBNU Pantau Pengolahan Arsip NU di ANRI.

Alwi Shihab. Membendung Arus Respon Gerakan Muhammadiyah Terhadap Penetrasi Misi Kristen Di Indonesia. Bandung: Mizan, 1998.

Arif Rahman Bramantya. "Jejak Organisasi Asrama Ratnaningsih: Digitalisasi Sebagai Upaya Penyelamatan Arsip." Diplomatika 1, no. September 2017 (2017): 2437.

Arsip Nasional Republik Indonesia. "MoU ANRI Dengan PP Muhammadiyah Akan Laksanakan Pengarsipan Arsip Kuno Dan Modern Milik Muhammadiyah." Arsip Nasional Republik Indonesia, 2015. http://www.anri. go.id/detail/187-MoU-ANRIdengan-PP-Muhammadiyahakan-Laksanakan-PengarsipanArsip-Kuno-dan-Modern-MilikMuhammadiyah.

- Peraturan Kepala Arsip Nsaional Republik Indonesia
Nomor 7 Tahun 2017 Tentang Gerakan Nasional Sadar Tertib Arsip. Jakarta: Arsip Nasional Republik Indonesia, 2017. http:// www.anri.go.id/assets/collections/ files/Perka_7_2017.pdf.

Creswell, John W. Research Design Pendekatan Kualitatif, Kuantitatif, Dan Mixed. 3rd ed. Yogyakarta: Pustaka Pelajar, 2010.

David Efendi. "Tantangan Pengeloaan Arsip Muhammadiyah." Majelis Pustaka dan Informasi Pimpinan Pusat Muhammadiyah, 2016.

Hilmy Muhammdiyah \& Sulthan Fatoni. NU: Identitas Islam Indonesia. Jakarta: eLSAS, 2004.

Judith Ellis. Keeping Archives. 2nd ed. Australia: The Australian Society of Archivist, 1993.

Kacung Marijan. Quo Vadis NU; Setelah Kembali Ke Khittah 1926. Jakarta: Erlangga, 1992.

Lince Eppang. "Arsip Muhammadiyah Diselamatkan Agar Tidak Ada Penyesatan Informasi Di Masa Depan." Netralnews.com, 2016. http://www.netralnews.com/ news/religi/read/40505/arsip. muhammadiyah.diselamatkan. agar.tidak.ada.penyesatan . informasi.di.masa.depan.

Mastur. "Wawancara Dengan Sekretaris PBNU." Jakarta, n.d.

Muhammad ASh-Shalabi. The Great Leader of Umar Bin AlKhathab ; Kisah Kehidupan Dan Kepemimpinan Khalifah Kedua. Jakarta: Pustaka Al-Kautsar, 2008.

Muhammadiyah, Majelis Pustaka dan Informasi Pimpinan Pusat. "Jabaran Program MPI 20152020." Muhammadiyah, 2017. http://mpi.muhammadiyah.or.id/ content-16-sdet-jabaran-program. html. 
Nahdatul Ulama. "Melongok Perpustakaan PBNU." $\mathrm{Nu}$ Online, 2012. http://www.nu.or. $\mathrm{id} / \mathrm{post} / \mathrm{read} / 41234 / \mathrm{melongok}$ perpustakaan-pbnu.

Nahdlatul Ulama. "Badan Otonom." Nu Online, 2015. http://www.nu.or.id/ about/badan+otonom.

-. "Jaringan." $\mathrm{Nu}$ Online, 2015. http://www.nu.or.id/about/ jaringan.

-. "Lembaga." $\mathrm{Nu}$ Online, 2015. http://www.nu.or.id/about/ lembaga.

Nina. "Wawancara Dengan Kepala Perpustakaan Pengurus Besar Nahdatul Ulama." Jakarta, 2017.

Pimpinan Pusat Muhammdiyah. "Struktur Organisasi." Pimpinan Pusat Muhhamadiyah, 1997. http:// www.muhammadiyah.or.id/id/ content-54-det-struktur-organisasi. html.

Republik Indonesia. "Peraturan Pemerintah Republik Indonesia Nomor 28 Tahun 2012 Tentang Pelaksanaan Undang-Undang Nomor 43 Tahun 2009 Tentang Kearsipan.” Jakarta, 2012. http://www.anri.go.id/assets/ download/58PP-No-28-Tahun2012-tentang-Pelaksanaan-UUNo-43-Tahun-2009.pdf.

_. "Undang-Undang Nomor 7 Tahun 1971 Tentang KetentuanKetentuan Pokok Kearsipan." Jakarta, 1971. http://www.anri. go.id/assets/download/82UUNomor-7-Tahun-1971-TentangKetentuan-Pokok-Kearsipan.pdf.

_. "Undang-Undang Republik Indonesia Nomor 43 Tahun 2009 Tentang Kearsipan." Jakarta, 2009. http://www.anri.go.id/assets/ download/87Nomor-43 - Tahun2009-Tentang-Kearsipan.pdf.

Roni Thabroni. "Pameran
Arsip Muhammadiyah.” Muhammadiyah, 2012.

Sudarnoto Abdul Hakim. "Merawat Catatan Mbah-Mbah Muhammadiyah.” R Boekoe Radio Buku, 2015.

Sue McKemmish. Introducing Archives and Archival Programs. Dalam Judith Ellis (Ed.). Keeping Archives. 2nd ed. Port Melbourne: DW Thrope, 1993.

Sugiono. Metode Peneliian Manajemen. Bandung: Alfabeta, 2016. 